second dose has proven safe after 4 hours.

\title{
ACTH vs VIGABATRIN IN INFANTILE SPASMS
}

The comparative efficacy and safety of ACTH $(110 \mathrm{IU} / \mathrm{m} 2$ once daily for 15 days) and vigabatrin $(100-150 \mathrm{mg} / \mathrm{kg} /$ daily in bid doses) was evaluated by a retrospective analysis of medical records of 42 infants (21 in each group) with infantile spasms and hypsarrhythmia treated at the Universite de Montreal, Hopital Sainte-Justine, Montreal, Canada. Seizure response was similar in the ACTH and vigabatrin-treated infants at 12 month follow-up (61\% vs $71 \%$ benefited, respectively), but vigabatrin was better tolerated than ACTH. Side effects of ACTH in 5 patients included hypertension and Cushing's syndrome, requiring discontinuation of therapy in 3; hypotonia and sleep disturbance in 3 vigabatrintreated patients were transient and did not require drug withdrawal. No cases of visual field restriction were encountered. Vigabatrin was recommended as the first-line treatment for infantile spasms. (Cossette P, Riviello JJ, Carmant L. ACTH versus vigabatrin therapy in infantile spasms: a retrospective study. Neurology May 1999;52:1691-1694). (Reprints: Dr Lionel Carmant, Service de Neurologie, Hopital Sainte-Justine, 3175, Cote Sainte-Catherine, Montreal, Qc, H3T 1C5 Canada).

COMMENT. Vigabatrin and ACTH appear to show equal effectiveness in the treatment of infantile spasms, but the plethora of reports of vigabatrin-induced visual field defects in adults are a concern. The majority of the cases cited are in adults, but asymptomatic visual field constriction also occurs in children. Two affected children, ages 10 and 15, treated with vigabatrin in doses ranging from 1000 to $3500 \mathrm{mg} / \mathrm{kg}$, are reported from the Children's Hospital, University Hospital of Kuopio, Finland. (Vanhatalo S, Paakkonen L. Neurology May 1999;52:1713-1714).

At least with long-term therapy, vigabatrin should be used with caution in infants, until more is known about the risk factors involved.

\section{PERIVENTRICULAR HETEROTOPIA AND ABSENCE EPILEPSY}

A 7-year-old child with absence seizures and a $3-\mathrm{Hz}$ generalized and occasional focal, spike-and-wave EEG pattern, responsive to treatment with valproic acid, had an MRI with periventricular nodular heterotopias, primarily right sided. The neurologic examination was normal. (Giza CC, Kuratani JD, Cokely H, Sankar R. Periventricular nodular heterotopia and childhood absence epilepsy. Pediatr Neurol April 1999;20:315-318). (Respond: Dr Raman Sankar, Pediatric Neurology, Box 951752, UCLA School of Medicine, Los Angeles, CA 90095).

COMMENT. Focal abnormalities in an otherwise typical and generalized EEG pattern for childhood absence epilepsy prompted an MRI in this case which uncovered the unexpected cerebral migration lesion.

\section{NOCTURNAL FRONTAL LOBE EPILEPSY}

The clinical and polysomnographic findings in 100 consecutive cases of nocturnal frontal lobe epilepsy (NFLE) were analysed in a study at the Neurological Institute, University of Bologna, Italy. Males predominated, in a male/female ratio of $7: 3$. Nocturnal paroxysmal episodes presented at any age from 1 to 64 years (mean $14+/-10$ years) but mainly during infancy and adolescence; parasomnias in infancy were followed by NFLE seizures after intervals of 1 to 30 years. A family history of epilepsy or parasomnias occurred in $25 \%$ or $39 \%$, respectively. Past histories included sleep disorders (talking, enuresis, head banging, and sleep walking) in early childhood; 7 had birth anoxia, 3 febrile convulsions, and 3 antecedent mild head trauma. CT or MRI 